\title{
Carnets
}

Revue électronique d'études françaises de l'APEF

Deuxième série - 15 | 2019

Jules Verne et les pouvoirs de l'imagination

\section{Condições materiais da imaginação criativa}

o tempo de Júlio Verne

Joaquim da Costa Leite

\section{(2) OpenEdition}

Journals

Edição electrónica

URL: http://journals.openedition.org/carnets/9529

DOI: $10.4000 /$ carnets.9529

ISSN: 1646-7698

Editora

APEF

Refêrencia eletrónica

Joaquim da Costa Leite, « Condições materiais da imaginação criativa », Carnets [Online], Deuxième série - 15 | 2019, posto online no dia 31 janeiro 2019, consultado o 19 abril 2019. URL : http://

journals.openedition.org/carnets/9529; DOI : 10.4000/carnets.9529

Este documento foi criado de forma automática no dia 19 Abril 2019.

\section{(c) (1) (8)}

Carnets est mis à disposition selon les termes de la licence Creative Commons - Atribution - Pas d'utilisation commerciale 4.0 International. 


\section{Condições materiais da imaginação criativa}

O tempo de Júlio Verne

Joaquim da Costa Leite

\section{Abertura}

1 O tempo de Júlio Verne (1828-1905) foi um período extraordinário de tensão dinâmica entre a tradição - marcada pelo ciclo repetido das estações do ano, com práticas e valores herdados de gerações passadas, - e o progresso assente na tecnologia industrial, com uma expectativa de mudança contínua.

A ideia de progresso, materializada na Revolução Industrial, de que o presente já não era apenas uma repetição do passado, permitia simultaneamente reinterpretar o passado e imaginar o futuro sem as condicionantes do presente. Era possível conceber e produzir obras radicalmente inovadoras como as viagens extraordinárias imaginadas por Júlio Verne, as propostas de Karl Marx sobre o papel do movimento operário, ou a origem das espécies segundo Charles Darwin. Obras que iam ao encontro de novos públicos, lidas, traduzidas e divulgadas em diversas línguas; nos casos mais controversos eram debatidas vigorosamente por fervorosos adeptos e ferozes opositores, no contexto de uma opinião pública internacional em formação.

Para perceber esta mudança no ambiente intelectual, comecemos pela economia.

\section{Da economia maltusiana à economia industrial}


Gráfico 1. Índice de salários reais de ajudantes de pedreiro em Inglaterra (Clark, 2005).

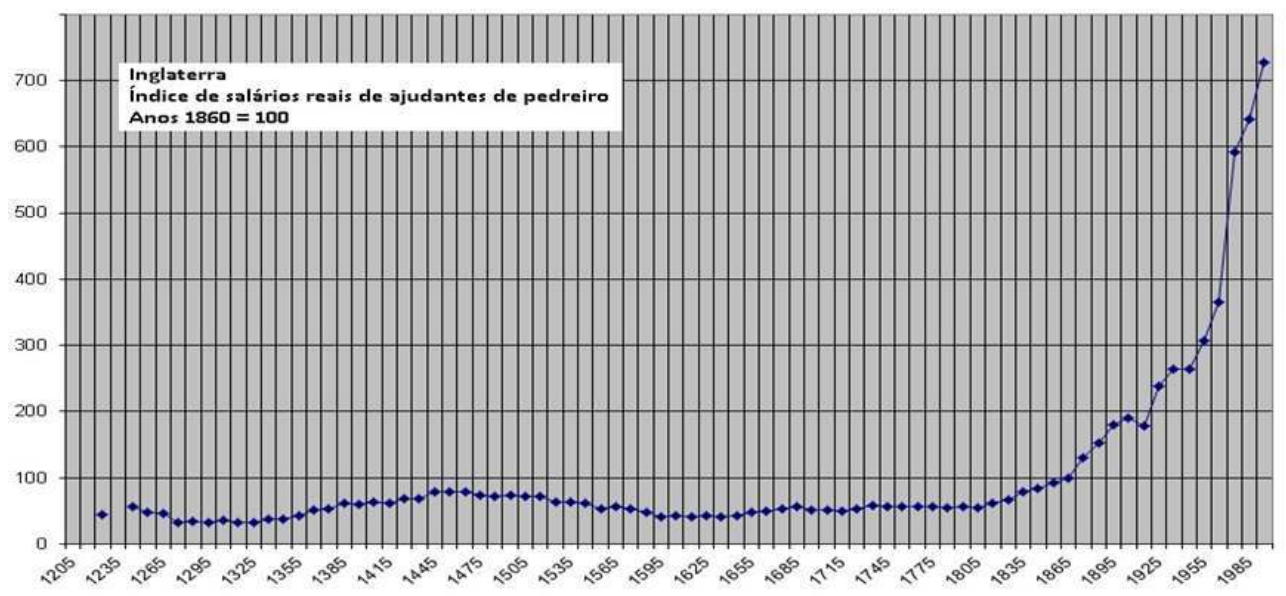

2 O gráfico 1 apresenta um índice dos salários reais de ajudantes de pedreiro em Inglaterra desde o século XIII ao século Xx. Com todas as suas limitações, o índice sintetiza a evolução de longo prazo do poder de compra de trabalhadores não qualificados, ilustrando uma extraordinária mudança: depois de séculos de uma economia que podemos considerar maltusiana, em que grandes crises de mortalidade como a Peste Negra resultavam num aumento dos salários reais, enquanto o crescimento demográfico pressionava no sentido da baixa salarial, o século XIX regista o início do crescimento sustentado do poder de compra dos salários, atingindo níveis sem precedentes.

3 A evolução, geralmente identificada com a Revolução Industrial, tinha começado de forma modesta, antes de se tornar evidente nas máquinas movidas por novas formas de energia, em grandes concentrações fabris. Em 1776, Adam Smith descrevia em A Riqueza das Nações o fabrico de alfinetes, em condições que aos nossos olhos se afiguram uma simples produção artesanal; no entanto, o cerne da descrição assenta na divisão do trabalho, numa lógica organizativa conducente à industrialização. Em vez do método tradicional em que cada artesão executava todas as operações do princípio ao fim, na oficina descrita por Adam Smith a produção de alfinetes era executada numa sequência de operações, cada uma entregue a um trabalhador especializado. Assim, com o mesmo número de trabalhadores, a divisão do trabalho permitia aumentar a produção, conjugando três vantagens: aumentava a destreza dos trabalhadores, cada um na respetiva operação; poupava tempo na mudança de trabalhadores entre operações; e estimulava a invenção de máquinas que facilitavam e simplificavam o trabalho, permitindo que, na expressão de Adam Smith, « um homem fizesse o trabalho de muitos » (Smith, 1994 :7).

4 A divisão do trabalho dependia da extensão do mercado, uma realidade que nesse final do século XVIII evoluía favoravelmente, e iria acelerar ao longo do século xIx. Com efeito, diferentes fatores contribuíam para o alargamento do mercado : desde logo, o aumento da população que nessa época se verificava por toda a Europa, e em especial na sua componente urbana, com destaque para a Inglaterra em processo de industrialização ; as melhorias e inovações nos sistemas de informação, transportes e logística, que alargavam a área geográfica do mercado ao alcance dos produtores ; o aumento do poder de compra de cada vez mais setores da população; e finalmente, a acumulação de capital, a mecanização e o aumento da escala de produção que resultaram na redução do custo 
unitário de produção, numa realização sem precedentes da era industrial, concretizada inicialmente na fiação de algodão, e gradualmente conseguida noutros produtos. A conjugação destes fatores fazia com que os produtores pudessem contar com um mercado em crescimento, estimulando o investimento, e por sua vez os consumidores beneficiassem com produtos mais acessíveis em quantidade, qualidade e preço, ganhando em poder de compra. Sem perder de vista que todo este processo cumulativo, habitualmente descrito pelo lado da produção, destacando industriais, comerciantes e agricultores, assentava no aumento da produtividade do trabalho, claramente analisada por Adam Smith.

5 Neste contexto, a interpretação de Adam Smith permite compreender a lógica que conduziu a um aumento sustentado da produtividade do trabalho, resultando mais tarde ou mais cedo na melhoria salarial e aumento do poder de compra dos trabalhadores, a começar pelos trabalhadores especializados. $O$ índice de salários reais dos ajudantes de pedreiro mostra que o aumento da produtividade média da economia, sustentado no tempo, chegava também, de forma mensurável, aos trabalhadores não qualificados e, nessa medida, à generalidade da população.

\section{Industrialização, economia e sociedade}

6 O processo de industrialização, primeiro discreto e praticamente sem máquinas, em sectores e regiões circunscritas, depois cada vez mais forte, recorrendo a novas formas de energia, dentro e fora das fábricas, alterou as condições de produção, distribuição e consumo, desenvolvendo grandes concentrações urbano-industriais nos centros de uma moderna rede de transportes e comunicações.

A fase inicial decorreu de forma modesta, usando e adaptando a força humana e animal, as formas de energia tradicionais do vento e da água, ou simplificando e dividindo operações como na fábrica de alfinetes descrita por Adam Smith. Gradualmente, porém, inventores e inovadores, com grande sentido prático, começaram a aproveitar as oportunidades da economia em crescimento, desenvolvendo máquinas eficientes de aplicação industrial. No final dos anos setenta do século dezoito as máquinas a vapor concorriam já com as rodas de água como energia motriz nas fábricas de fiação de algodão. $\mathrm{E}$ ao contrário da água e do vento, que tendiam à dispersão territorial, o vapor favorecia a concentração industrial e mostrava capacidade de adaptação a diferentes usos e equipamentos, movendo máquinas, locomotivas e caldeiras. Em 1825 era inaugurada em Inglaterra a primeira linha de caminho-de-ferro, iniciando uma nova era de grandes investimentos em infraestruturas de comunicações e transportes, em terra e no mar.

7 Esta nova economia era comandada pelas grandes regiões industriais, em cada vez mais países, interagindo entre si, multiplicando relações de concorrência e complementaridade; o seu elevado poder de compra criava novos hábitos de consumo, novos canais de distribuição, novas formas de negócio; com a sua desproporcionada capacidade de produção e consumo, as regiões industriais exerciam múltiplas influências sobre as áreas rurais, desde a troca de produtos à atração migratória, com zonas de influência que podiam atingir dimensão internacional, como era particularmente evidente em cidades como Manchester e Londres.

A esta escala, as mudanças na economia tinham profundas repercussões sociais, obrigando a uma recomposição da organização política da sociedade orientada, sobretudo na Europa e Américas, para a formação de sistemas constitucionais de governo. Numa 
evolução complexa, a recomposição das sociedades tradicionais dependia essencialmente das condições internas de cada país, mas era influenciada cada vez mais por fatores internacionais de imitação e concorrência.

Da descoberta científica às patentes industriais, do telégrafo ao caminho-de-ferro, da navegação a vapor às obras de engenharia, das tipografias às instalações fabris e cabos submarinos, nos meados do século XIX a mudança assumia uma natureza multidimensional globalizada.

A Grande Exposição do Palácio de Cristal em Londres, inaugurada em 1851, pode ser tomada simultaneamente como realização e símbolo dos novos tempos. Concebida como The Great Exhibition of the Works of Industry of all Nations (era esse o título oficial), foi montada em tempo recorde, dentro do orçamento previsto. Na sua preparação, o Príncipe Alberto explicou a ministros, embaixadores estrangeiros, comissários da exposição e presidentes de câmara reunidos num banquete a 21 de março de 1850, a importância e significado da exposição, destacando as caraterísticas da nova era :

Nobody (...) who has paid any attention to the peculiar features of our present era, will doubt for a moment that we are living at a period of most wonderful transition, which tends rapidly to accomplish that great end, to which, indeed, all history points - the realisation of the unity of mankind. Not a unity which breaks down the limits and levels the peculiar characteristics of the different nations of the earth, but rather a unity, the result and product of those very national varieties and antagonistic qualities.

The distances which separated the different nations and parts of the globe are rapidly vanishing before the achievements of modern invention, and we can traverse them with incredible ease; the languages of all nations are known, and their acquirement placed within the reach of everybody; thought is communicated with the rapidity, and even by the power, of lightning. On the other hand, the great principle of division of labour, which may be called the moving power of civilisation, is being extended to all branches of science, industry, and art (Alberto, 1879:204-5).

9 Falando na qualidade de Consorte da Rainha Vitória, o príncipe alemão, parente próximo das casas reinantes da Europa, referia explicitamente o grande princípio da divisão do trabalho analisado por Adam Smith, integrando-o numa visão cosmopolita, de progresso tendente à realização da unidade da Humanidade, em que o pensamento era comunicado com a rapidez do relâmpago.

\section{Novas possibilidades do pensamento radical}

Nos meados do século XIX a evidência do progresso convencia cientistas e filósofos, leitores e viajantes : como dizia o Príncipe Alberto, vivia-se um período de maravilhosa transição. E se o presente já não era apenas uma repetição do passado, era admissível pensar que o futuro seria diferente do presente.

Abria-se a possibilidade de ultrapassar as barreiras do pensamento tradicional ; mais além da liberdade lógica e filosófica assim conquistada, as novas condições económicas, sociais e políticas permitiam debater e testar novas ideias, experimentar novas formas de organização, atingir novos públicos.

11 Neste quadro histórico, encontramos autores que, nas áreas mais diversas, demonstram a exploração de ideias radicais, dificilmente pensáveis em 1800. Três exemplos, por ordem cronológica: em 1848 Karl Marx e Friedrich Engels publicam o Manifesto do Partido Comunista ; em 1859 Charles Darwin publica A Origem das Espécies; e Júlio Verne inicia em 
1863, com a publicação de Cinco Semanas em Balão, a série conhecida como Viagens Extraordinárias.

o processo de industrialização dependia não apenas de um número crescente de trabalhadores, mas de novos grupos profissionais concentrados em grandes centros urbanos, geralmente desligados das origens rurais e dos enquadramentos sociais tradicionais. Diferentes partidos e movimentos - entre os quais os comunistas procuravam atrair e organizar as novas classes trabalhadoras, desafiando a sociedade tradicional.

12 Independentemente do seu acerto ou desacerto, importa destacar o quadro histórico que tornou possível o pensamento de Marx e as suas propostas de ação. Em contraste com a clássica Utopia de Thomas More, o ideal comunista de Karl Marx configurava um objetivo real, inspirador da ação organizada para a mudança, necessariamente violenta, da ordem social. O II Congresso da Liga Comunista, realizado em Londres no final de 1847, encarregou Karl Marx e Friedrich Engels de redigirem um programa de ação, na forma de um manifesto. Assim nasceu o Manifesto do Partido Comunista, afirmando logo na introdução que o comunismo existia já como um poder temido pelas potências europeias :

A spectre is haunting Europe - the spectre of communism. All the powers of old Europe have entered into a holy alliance to exorcise this spectre: Pope and Tsar, Metternich and Guizot, French Radicals and German police-spies.

Where is the party in opposition that has not been decried as communistic by its opponents in power? Where is the opposition that has not hurled back the branding reproach of communism, against the more advanced opposition parties, as well as against its reactionary adversaries?

Two things result from this fact:

I. Communism is already acknowledged by all European powers to be itself a power.

II. It is high time that Communists should openly, in the face of the whole world, publish their views, their aims, their tendencies, and meet this nursery tale of the Spectre of Communism with a manifesto of the party itself.

To this end, Communists of various nationalities have assembled in London and sketched the following manifesto, to be published in the English, French, German, Italian, Flemish and Danish languages (Marx \& Engels, 201: 14)

13 Colocando em primeiro plano a questão da propriedade dos meios de produção, e afirmando sem qualquer hesitação a sua natureza revolucionária, sem fronteiras, o Manifesto discutia a posição a adotar relativamente a outros partidos de oposição nos diferentes países, comprometendo-se a apoiar todos os movimentos dirigidos contra a ordem política e social existente. Sem disfarce, ameaçava derrubar pela força as classes dirigentes, numa revolução comunista. O Manifesto do Partido Comunista terminava exortando à união os proletários de todos os países :

(...) the Communists everywhere support every revolutionary movement against the existing social and political order of things.

In all these movements, they bring to the front, as the leading question in each, the property question, no matter what its degree of development at the time.

Finally, they labour everywhere for the union and agreement of the democratic parties f all countries.

The Communists disdain to conceal their views and aims. They openly declare that their ends can be attained only by the forcible overthrow of all existing social conditions. Let the ruling classes tremble at a Communistic revolution. The proletarians have nothing to lose but their chains. They have a world to win.

Working Men of All Countries, Unite! (Marx \& Engels, $2010: 34$ ).

Ao contrário do Manifesto, as teorias de Charles Darwin não representavam, pelo menos no imediato, qualquer ameaça à ordem social existente, mas o seu potencial 
revolucionário não era inferior ao projeto marxista. Com efeito, A Origem das Espécies contraditava a ideia da criação independente de cada espécie, uma ideia que o próprio Darwin partilhara com a maioria dos naturalistas, mas fora obrigado a abandonar, após estudo metódico e apreciação desapaixonada :

Although much remains obscure, and will long remain obscure, I can entertain no doubt, after the most deliberate study and dispassionate judgment of which I am capable, that the view which most naturalists entertain, and which I formerly entertained - namely, that each species has been independently created - is erroneous. I am fully convinced that species are not immutable; but that those belonging to what are called the same genera are lineal descendants of some other and generally extinct species, in the same manner as the acknowledged varieties of any one species are the descendants of that species. Furthermore, I am convinced that Natural Selection has been the main but not exclusive means of modification (Darwin, 2004: 14).

Esta formulação, cautelosa e aparentemente inócua quando analisada à distância do tempo, negava a criação do ser humano como ser completo, perfeitamente formado e, nessa medida, recusava o ato divino da criação, tal como ele era tradicionalmente interpretado pelas grandes religiões. Ao argumentar que as espécies não eram imutáveis, antes tinham evoluído a partir de uma origem comum por um processo de diferenciação, essencialmente, mas não exclusivamente, explicado pela seleção natural, o autor não defendia um postulado filosófico ou uma preferência moral: deduzia cientificamente, com base na evidência recolhida e analisada ao longo de décadas, em contacto com outros especialistas.

Desde a expedição do navio Beagle (1831-36) às publicações e debates, incluindo a participação em sociedades científicas e a correspondência com outros estudiosos, $A$ Origem das Espécies não era fruto isolado do génio e capacidade de trabalho de Charles Darwin ; os seus contactos e redes de conhecimento configuravam condições modernas da produção de conhecimento. Isso era traduzido, por exemplo, na introdução em que o autor agradecia coletivamente a generosa assistência recebida de muitos naturalistas, alguns dos quais nem conhecia pessoalmente. E apesar da extensão da obra, Darwin chamava-lhe modestamente um resumo - Abstract é a palavra usada, - justificando a urgência da sua publicação, que não lhe permitia dar as referências e autoridades que fundamentavam todas as suas afirmações :

This Abstract, which I now publish, must necessarily be imperfect. I cannot here give references and authorities for my several statements; and I must trust to the reader reposing some confidence in my accuracy. No doubt errors will have crept in, though I hope I have always been cautious in trusting to good authorities alone. I can here give only the general conclusions at which I have arrived, with a few facts in illustration, but which, I hope, in most cases will suffice. No one can feel more sensible than I do of the necessity of hereafter publishing in detail all the facts, with references, on which my conclusions have been grounded; and I hope in a future work to do this. For I am well aware that scarcely a single point is discussed in this volume on which facts cannot be adduced, often apparently leading to conclusions directly opposite to those at which I have arrived. A fair result can be obtained only by fully stating and balancing the facts and arguments on both sides of each question; and this cannot possibly be here done.

I much regret that want of space prevents my having the satisfaction of acknowledging the generous assistance which I have received from very many naturalists, some of them personally unknown to me (Darwin, 2004:10).

16 A esta luz, a obra de Júlio Verne constitui um outro exemplo de pensamento radical, imaginando e descrevendo viagens extraordinárias, em condições nunca antes realizadas. 
Apaixonado pela ciência e tecnologia, muito bem informado sobre a sociedade contemporânea, o autor projetava no futuro veículos e soluções que a indústria da época ainda não conseguia construir, mas que um grande número de leitores conseguia imaginar, acompanhando os heróis dos romances até ao centro da Terra, numa longa expedição submarina, ou deixando o nosso planeta numa viagem à Lua. Em tempos de transformação industrial, Júlio Verne não era um Leonardo da Vinci sonhando aparelhos de construção impossível, mas alguém que antecipava o futuro que um dia teria lugar, como em Paris no Século XX.

Curiosamente, apesar de muitos leitores de Júlio Verne considerarem o autor como um escritor de ficção científica, o seu objetivo seria um pouco diferente, a avaliar pelo que escrevia em 1888 numa carta ao editor: "Le but poursuivi par l'auteur des Voyages extraordinaires est de dépeindre le Monde entier sous la forme du roman géographique et scientifique » (Dupuy, 2013).

Assim, não será despropositado apontar o significado histórico de A Volta ao Mundo em Oitenta Dias, obra ficcionada pelos personagens e aventuras, mas extraordinariamente realista e atualizada no que dizia respeito às infraestruturas de comunicações e transportes que em 1873 permitiriam dar a volta ao mundo.

\section{A volta ao mundo em oitenta dias}

18 A industrialização tinha produzido um efeito de globalização. As infraestruturas de comunicações e transportes, que permitiam a circulação de mercadorias, facilitavam também a circulação de informação, pessoas e ideias. Se a realização da unidade da Humanidade era ainda um objetivo distante nos termos idealizados pelo Príncipe Alberto, o encurtamento das distâncias que separavam as diferentes nações e partes do globo era patente em milhares de quilómetros de caminho-de-ferro construídos, nas linhas regulares de navegação a vapor que ligavam os continentes, nas linhas de telégrafo e cabos submarinos.

Para um observador atento como Júlio Verne, as diversas componentes do emaranhado de notícias de âmbito económico, tecnológico e geográfico, sugeriam a possibilidade real de completar uma volta ao mundo em tempo recorde, usando as novas infraestruturas que permitiam viajar, mantendo simultaneamente a comunicação com familiares e amigos ao longo da viagem. Nesse contexto real, Júlio Verne imaginou a história e os personagens de A Volta ao Mundo em Oitenta Dias.

A história começa em Londres, escolha natural para uma viagem à volta do mundo. A capital britânica era o centro da economia globalizada, a maior praça financeira, centro da rede internacional de transportes, sede das maiores companhias de navegação e da seguradora Lloyds, o maior segurador marítimo. Quando, em 1876, a Rainha Vitória do Reino Unido da Grã-Bretanha e Irlanda, acrescentou o título de Imperatriz da Índia, governava sobre territórios onde, como se dizia na época, o sol nunca se punha.

Os ingleses estavam habituados a viajar, seguros da proteção conferida pelo estatuto de súbditos de Sua Majestade. No plano individual estavam dispensados do serviço militar, não careciam de passaporte ou outro documento de identificação, podendo deixar o país quando entendessem, sem qualquer formalidade, levando consigo os seus bens, sem qualquer restrição. 
20 Assim, quando Phileas Fogg, o herói do romance, faz a aposta de dar a volta ao mundo em oitenta dias, afirma-se pronto a partir nessa mesma noite no comboio para Dover, dando início à viagem; dispondo de vinte mil libras - « um grande maço de notas do Banco de Inglaterra, que seriam válidas por onde quer que passasse» - deu ordem ao criado Passepartout para preparar um saco de viagem com duas camisas e três pares de meias para si, o mesmo para o criado; comprariam pelo caminho as roupas que precisassem (Verne, 2004 :23-26). Dramatizando, o autor francês exagerava até à caricatura o método, pontualidade e gosto das apostas atribuídas aos ingleses, mas as movimentações concretas correspondiam aos usos e costumes da sua liberdade.

A aposta resultara de uma discussão com os parceiros no jogo de whist, no Reform Club, a propósito da grande notícia do dia, um assalto ao Banco de Inglaterra. Contrariando um dos jogadores, que afirmava que o mundo era suficientemente grande para o assaltante desaparecer, Phileas Fogg retorquiu que isso era antigamente; na troca de argumentos, um outro jogador, concordando com Phileas Fogg, defendia que «o mundo ficou mais pequeno, desde que uma pessoa pode contorná-lo dez vezes mais depressa do que há cem anos atrás » (Verne, 2004 :18). Na sequência, outro parceiro mostrou uma estimativa do Daily Telegraph, detalhando escalas e dias de viagem, somando oitenta dias como o tempo necessário para dar a volta ao mundo.

Quadro 1. Estimativa de itinerário e dias de viagem (Verne, $2004: 19)$.

\begin{tabular}{|l|l|}
\hline Itinerário : Escalas & Dias de viagem \\
\hline De Londres para Suez via Mont Cenis e Brindisi, de comboio e navio a vapor & 7 \\
\hline De Suez para Bombaim, de navio a vapor & 13 \\
\hline De Bombaim para Calcutá, de comboio & 3 \\
\hline De Calcutá para Hong Kong, de navio a vapor & 13 \\
\hline De Hong Kong para Iocohama (no Japão), de navio a vapor & 6 \\
\hline De Iocohama para São Francisco, de navio a vapor & 22 \\
\hline De São Francisco para Nova Iorque, de comboio & 7 \\
\hline De Nova Iorque para Londres, por navio a vapor e comboio & 9 \\
\hline Total & 80 \\
\hline
\end{tabular}

21 Teria Júlio Verne lido em algum jornal a estimativa, reproduzida no quadro 1 ? Não seria surpreendente, como não seria difícil ao autor elaborar a sua própria estimativa. No início dos anos 70 do século XIX os horários de comboios e vapores eram publicados regularmente em folhetos, almanaques e anuários postais, para informação de um número crescente de viajantes, agentes e outras pessoas interessadas na receção e expedição de correspondência, incluindo emigrantes e seus familiares, funcionários, comerciantes e industriais.

O itinerário proposto fazia a ligação entre grandes portos e terminais ferroviários, usando 
algumas infraestruturas completadas recentemente, com destaque para o período 1869-71. Por exemplo, a ligação ferroviária de São Francisco a Nova Iorque foi inaugurada a 10 de maio de 1869 ; nesse mesmo ano, a 17 de novembro, foi inaugurado o Canal de Suez, poupando uma viagem longa e perigosa, contornando o continente africano pela rota do Cabo. Poucos meses depois, a 7 de março de 1870, foi inaugurada oficialmente a ligação ferroviária de Bombaim a Calcutá.

O túnel de Fréjus ou Mont Cenis, que assegurava a travessia dos Alpes entre a França e Itália, foi inaugurado em setembro de 1871, e a primeira viagem de comboio entre Paris e Roma foi realizada no mês seguinte. A travessia, anteriormente demorada e praticável apenas com bom tempo, passava a ser uma viagem relativamente confortável, com horários regulares.

Ilustração 1. Itinerário esquemático de $A$ Volta ao Mundo em Oitenta Dias.

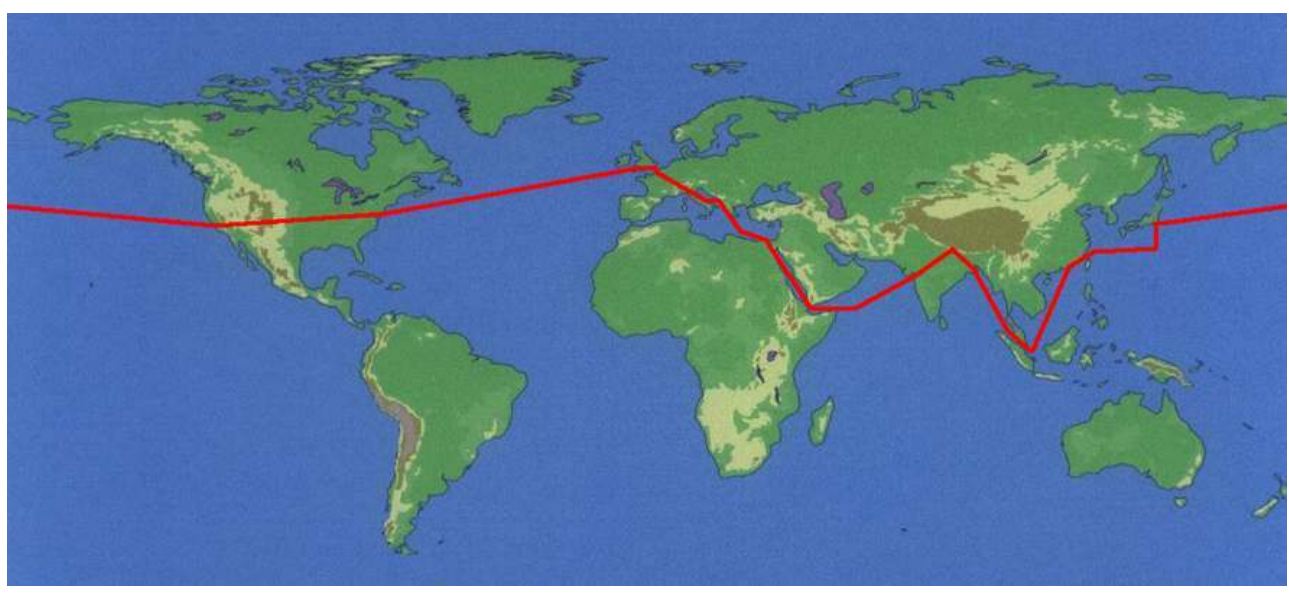

A ilustração 1 dá uma ideia de conjunto. Tratava-se de grandes infraestruturas, exigindo vultuosos investimentos, nalguns casos constituindo também grandes feitos de engenharia. A maior parte justificou cerimónias de inauguração oficial, documentadas em fotografias e outros registos, contando com a presença de correspondentes de jornais e revistas. Por exemplo, a inauguração do Canal de Suez foi uma cerimónia internacional realizada com pompa e circunstância, descrita por Eça de Queiroz, que assistiu na companhia do conde de Resende (Eça de Queiroz, 1870).

23 Vale a pena acrescentar, com atenção à cronologia das inaugurações, o sentido de oportunidade e a rapidez com que Júlio Verne respondeu a essas notícias, concebendo e publicando o romance sob a forma de folhetim em 1872, como livro no ano seguinte.

\section{A concluir}

A história do pensamento criativo, tantas vezes simplificada como fruto do génio individual, no reino etéreo das ideias, ganha em ser interpretada no contexto material e social das condições em que as obras foram pensadas, construídas e divulgadas, seja no campo literário, científico, político ou filosófico.

No tempo de Júlio Verne, a transformação de uma economia tradicional de tipo maltusiano numa economia industrial, assegurou uma mudança sustentada nos sistemas de produção, distribuição e consumo. A mudança da economia, por sua vez, impulsionou uma transformação política e social, numa interação recíproca, multidimensional e 
globalizada. Neste novo contexto, o presente deixava de ser a repetição quase obrigatória do passado, e o futuro podia ser concebido com imaginação criativa.

Nos meados do século xIX a mudança era evidente e o campo de possibilidades afiguravase aberto a grandes transformações, desde a política de Karl Marx à ciência de Charles Darwin ou à literatura de Júlio Verne.

Autores e obras que não poderiam ser mais diferentes no tema, estilo, método e objetivos; no entanto, todos obrigam a repensar a relação entre passado, presente e futuro, questionando a natureza intemporal da humanidade ; todos suscitam questões de interesse universal, provocando discussão, atingindo um público internacional. E, cada um a seu modo, escreveu, debateu, estabeleceu redes de contacto e divulgação das suas ideias; ficaram famosos ainda em vida, partilhando a fama heterogeneamente com políticos, militares, industriais e banqueiros, ilustrando um novo tipo de celebridade propagandeado em jornais, revistas, clubes e associações, sem paralelo nas sociedades tradicionais. Mais do que o espírito do tempo, as suas obras demonstram a exploração intelectual da capacidade humana para mudar o mundo, nas condições materiais de uma nova era.

\section{BIBLIOGRAFIA}

ALBERTO, Príncipe Consorte da Rainha Vitória (1879). « Speech given at a banquet at the Mansion House on 21 March, 1850 », in Theodore Martin, The Life of His Royal Highness the Prince Consort. Volume 2, Nova Iorque : D. Appleton \& Co, pp. 204-205. [Consultado a 27 de outubro de 2018]. <URL: https://archive.org/details/lifehisroyalhig00martgoog/page/n2>.

CLARK, Gregory (2005). « The Condition of the Working Class in England 1209-2004 », Journal of Political Economy vol. 113, no 6, pp. 1307-1340.

DARWIN, Charles (2004). The origin of species. Londres : Collector's Library (1edição 1859).

DUPUY, Lionel (2013). « Les Voyages extraordinaires de Jules Verne ou le roman géographique au XIX siècle ", Annales de géographie no 690 pp. 131-150 [consultado a 8 de abril de 2018] <URL : https://https://www.cairn.info/revue-annales-de-geographie-2013-2-page-131.htm>.

EÇA DE QUEIROZ (1870). « De Port Said a Suez » in EÇA de QUEIROZ. Notas Contemporâneas. Lisboa : Edição Livros do Brasil, s.d., pp. 5-21.

MARX, karl \& ENGELS, Friedrich (2010). Manifesto of the Communist Party. (1 ${ }^{\text {a }}$ edição 1848). [Consultado a 26 de outubro de 2018] <URL : https://www.marxists.org/archive/marx/works/ download/pdf/Manifesto.pdf> SMITH, Adam (1994). The Wealth of nations. Nova Iorque : Modern Library (1edição 1776). VERNE, Júlio (2004). A Volta ao Mundo em Oitenta Dias. Porto : Público (1ª edição 1873). 


\section{RESUMOS}

O tempo de Júlio Verne (1828-1905) foi um período extraordinário de mudança. O processo de industrialização alterou os sistemas de produção, distribuição e consumo, estabelecendo as condições materiais de libertação da imaginação criadora do ser humano.

Se o presente já não era apenas uma repetição do passado, era admissível pensar que o futuro seria diferente do presente, abrindo assim a possibilidade de ultrapassar as barreiras do pensamento tradicional.

Neste quadro histórico, encontramos autores que, nas áreas mais diversas, demonstram a exploração de ideias radicais, dificilmente pensáveis em 1800. Três exemplos, por ordem cronológica : em 1848 Karl Marx e Friedrich Engels publicam o Manifesto do Partido Comunista ; em 1859 Charles Darwin publica a Origem das Espécies ; e Júlio Verne inicia em 1863 a série que seria conhecida como Viagens Extraordinárias com a publicação de Cinco Semanas em Balão.

The time of Jules Verne (1828-1905) was a period of extraordinary change. The process of industrialization altered the systems of production, distribution and consumption, establishing the material conditions for the liberation of the imaginative creation of the human being.

If the present was no longer just a repetition of the past, it was admissible to think that the future would be different from the present, thus opening the possibility of surpassing the barriers of traditional thinking.

Within this historical framework, we find authors who, in the most diverse areas, demonstrated the exploration of radical ideas, hardly thinkable in 1800. Three examples, by chronological order: in 1848 Karl Marx and Friedrich Engels published the Manifesto of the Communist Party; in 1859 Charles Darwin published The Origin of Species; and Jules Verne began in 1863 the series which would become known as Extraordinary Voyages with the publication of Five Weeks in a Balloon.

\section{ÍNDICE}

Keywords: industrialization, creative imagination, Marx (Karl), Darwin (Charles), Verne (Júlio) Palavras-chave: industrialização, imaginação criativa, Marx( Karl), Darwin (Charles), Verne (Júlio)

\section{AUTOR}

\section{JOAQUIM DA COSTA LEITE}

Universidade de Aveiro

j.costa.leite[at]ua.pt 